\title{
Sistema de Gestão de Custos para uma Secretaria Municipal de Saúde
}

\author{
Cost Management System for a Municipal Health Secretariat \\ Antonio Lopo Martinez \\ lopo@fucape.br \\ FUCAPE \\ Emilio Maltez Alves Filho \\ emaltez26@gmail.com \\ UNEB
}

\begin{abstract}
Resumo
Este artigo discorre sobre o desenvolvimento de um modelo conceitual de custos para uma Secretaria Municipal de Saúde (SMS). A partir de análises e pesquisas "in locu”, apresenta-se uma solução proposta para uma SMS de um município com mais de um milhão de habitantes. A despeito de peculiaridades no modus operandi da área pública, notadamente a flutuante cultura organizacional, procurou-se identificar as premissas mais relevantes para montagem de um sistema de acumulação de custos, chegando ao custo por unidade e por procedimento. A construção desse sistema de custos buscou atender às necessidades de avaliação, acompanhamento e controle da gestão orçamentária, financeira e patrimonial. Foi priorizado o desenvolvimento de um modelo geral e flexível, que possa ser aperfeiçoado gradativamente de acordo com a evolução da dinâmica cultural, organizacional e tecnológica do ente público.
\end{abstract} Palavras-chave: Custos. Gestão pública. Secretaria Municipal de Saúde.

\begin{abstract}
This article discusses the development of a conceptual cost model for a Municipal Health Secretariat (SMS). From analysis and research "in loco", it is presented a proposed solution for a SMS from a city with over a million inhabitants. Despite peculiarities in the modus operandi of the government, especially the floating organizational culture, we sought to identify the most relevant assumptions for structuring an accumulation cost system, even the cost per unit and procedure. The construction cost of this system sought to serve the needs assessment, monitoring and control of budgetary, financial and patrimonial. It prioritized the development of a general and flexible model, that can be improved gradually in accordance with the evolution of dynamic cultural, organizational and technological public entity.
\end{abstract}

Keywords: Costs. Public management. Municipal Health Secretariat

Artigo recebido em: 31.10.2012; Aceito em: 10.12.2012

\section{INTRODUÇÃO}

Qual a real utilidade de um sistema de gestão de custos no setor público? Em que medida tal instrumento irá atender aos interesses dos poderes executivos que se sucedem? Os atuais procedimentos legais de evidenciação das contas públicas propiciam mais transparência e mais controle de gastos, visando refletir eficiência e eficácia dos programas de governo? As possíveis respostas a essas questões geralmente têm servido como restrições à implantação de sistemas de custos e à avaliação do desempenho econômico e financeiro nessas entidades.

Este trabalho não se propõe a trazer soluções para essas questões, mas deverá propiciar uma contribuição para pelo menos três aspectos: a) apresentar um instrumento consistente que possa contribuir no aumento da transparência na gestão da coisa pública, restringindo seus gestores a agirem conforme os ditames e princípios da administração pública; b) apresentar mais um referencial concreto do desenvolvimento de um sistema de custos no setor público; e c) mostrar que o uso efetivo e sistemático deste tipo de instrumento poderá concretamente 
contribuir para melhoria da gestão orçamentária, financeira e patrimonial de uma entidade pública nos aspectos de eficiência e economicidade.

A busca das organizações governamentais por profissionalização, eficiência e efetividade vêm, cada vez mais, se configurando como uma prioridade. Através da implantação de instrumentos de mensuração que permitam um monitoramento sistemático de seu desempenho econômico e financeiro, estas entidades podem dar um grande salto de qualidade no que vem se denominando de "Nova Gestão Pública" e Governança.

Com um sistema de custos, o processo de avaliação de desempenho da gestão pública poderia ser melhorado através da monitoração de informações e indicadores, dos vetores ligados a efetividade em relação ao alcance das metas planejadas, qualidade dos serviços, processos e economicidade, que corresponde ao padrão de custos no alcance destas metas.

Através da análise de um caso real, são apresentados os principais aspectos, fundamentos e procedimentos necessários ao desenvolvimento e adequação de um sistema de custos para a área pública, em particular a Secretaria Municipal de Saúde. O caso mostra como os custos foram acumulados até se chegar ao custo por unidade e o custo por procedimento. O que se pretende destacar é a importância administrativa desse instrumento, que pode estimular e ampliar as possibilidades do gestor público na condução econômica e financeira do patrimônio público, principalmente através da otimização da função controle.

\section{Sistemas de GESTÃo de CUSTOS (SGC) PARA A ÁREA PÚBLICA}

Segundo Martins (2003), a escolha do Sistema depende do objetivo que com ele se pretende atingir; o seu nível de detalhes também depende disso e do quanto se gastará para sua obtenção. As informações são caras e sua utilidade não é igual em todos os níveis de detalhes. Sua adoção como "pacote" é temerária.

A dinâmica do processo decisório impõe ao gestor que sejam utilizados na gestão do dia-a-dia mais dados presentes e futuros do que dados passados e a combinar dados físicos com dados monetários. Esses aspectos tornam os sistemas de gestão de custos muito úteis, porquanto não dependem, necessariamente, da contabilidade "fechar" seu movimento para se saber qual foi o custo das operações do período. Essa peculiaridade gerencial propicia que um sistema de custos possa perfeitamente trabalhar com dados estimados e pré-estabelecidos. Para tanto, fazse necessário a utilização de técnicas auxiliares e, sobretudo, lógica, racionalidade, relevância e bom senso. (ROEHL-ANDERSON; BRAGG, 2009).

Para fundamentar as características que um sistema de gestão de custos (SGC) deve possuir no setor público, foram sintetizados alguns de seus objetivos em contraste com óticas de cultura organizacional pública (SLOMSKI, 2009):

Quadro 1 - Objetivos da gestão de custos versus filosofia da gestão pública

\begin{tabular}{|l|l|l|l|}
\hline $\begin{array}{l}\text { Objetivos da gestão de } \\
\text { custos }\end{array}$ & \multicolumn{1}{|c|}{ Gerencialismo puro } & \multicolumn{1}{|c|}{ Consumerismo } & \multicolumn{1}{|c|}{$\begin{array}{c}\text { Administração voltada } \\
\text { para o cidadão }\end{array}$} \\
\hline $\begin{array}{l}\text { Análise, planejamento e } \\
\text { controle }\end{array}$ & $\begin{array}{l}\text { Foco no curto prazo e e } \\
\text { equilíbrio fiscal. }\end{array}$ & $\begin{array}{l}\text { Foco na qualidade do } \\
\text { gasto público. }\end{array}$ & $\begin{array}{l}\text { Foco na qualidade do gasto e } \\
\text { observância das demandas } \\
\text { do cidadão. }\end{array}$ \\
\hline Processo decisório & $\begin{array}{l}\text { Não utilização de de } \\
\text { sistemas de custos }\end{array}$ & $\begin{array}{l}\text { Utilização de conceitos de } \\
\text { sistemas de custos }\end{array}$ & $\begin{array}{l}\text { Utilização de conceitos de } \\
\text { sistemas de custos }\end{array}$ \\
\hline Desempenho & Corte de gastos & Foco no valor & Foco em valor \\
\hline
\end{tabular}

Fonte:

Para a implantação bem sucedida de um sistema de gestão de custos no setor público, é necessário observar alguns elementos importantes que podem servir de guia (MACHADO, HOLANDA, 2010; PIGATTO et al.,2010): 
- Os sistemas de custeio devem estar integrados às realidades operacionais, organizacionais e físicas da entidade;

- Os diversos sistemas de informação existentes servirão de alimentação de dados primários para a gestão de custos;

- Deve-se iniciar o processo de gestão de custos com sistemas mais simples, mesmo com limitações, pois o setor público não possui ainda o padrão de aprendizagem necessária para a utilização de sistemas de custeio mais complexos e de alto custo de implantação.

- A implantação de sistemas de custos no setor público requer uma abordagem inter e multidisciplinar, abrangendo questões relativas à teoria mais atual sobre administração pública, ciência política, teoria de sistemas e organizações;

- As especificidades do setor público requerem a observância de fatores políticos, institucionais e culturais.

Entre os inúmeros benefícios que a implantação e o uso contínuo de sistemas de custos propiciariam para o setor público, poderiam ser destacados (SILVA, 1997; ALONSO, 1998; MACHADO, 2005; HOLANDA, LATTMANN-WELTMAN, GUIMARÃES, 2010):

a) $\mathrm{O}$ aperfeiçoamento da apreensão (captura) e delimitação dos valores que contribuirão para o desenvolvimento dos diversos processos e atividades, resultando nos custos dos vários serviços públicos disponibilizados;

b) $\mathrm{O}$ controle da economicidade das operações. $\mathrm{O}$ uso de um adequado planejamento e acompanhamento das atividades, avaliando a eficácia das operações, propiciará subsídio ao processo de tomada de decisões, com um efetivo controle de custos, redução de desperdícios, entre outros;

c) A melhoria do processo de planejamento. Com o detalhamento dos custos por centro de custos e a determinação dos custos totais de cada serviço disponibilizado, o orçamento seria muito melhor utilizado;

d) O dimensionamento e redução da capacidade ociosa, através da identificação da capacidade total e do grau de utilização desta pelo órgão ou unidade analisado;

e) A consequiente racionalização dos custos, otimizando a aplicação dos recursos públicos;

f) A avaliação, simulação e análise de alternativas, visando otimizar os processos e atividades de elaboração dos serviços públicos.

\section{METODOLOGIA DE GESTÃO DE CUSTOS}

\subsection{A Secretaria Municipal de Saúde (SMS)}

O caso a seguir foi desenvolvido na Secretaria Municipal de Saúde (SMS) de um munícipio brasileira de mais de um milhão de habitantes. A Secretaria Municipal de Saúde é um órgão de natureza jurídica da administração direta, subordinada ao prefeito do município, tendo como finalidade: Formular e executar a política de saúde pública do município. A finalidade da SMS se consubstanciará através das seguintes atividades:

- Planejamento e execução dos serviços públicos de saúde;

- Execução dos serviços de vigilância epidemiológica e sanitária;

- Serviço médico;

- Ação odontológica;

- Ação preventiva de saúde pública;

- Participação no desenvolvimento das ações e serviços do sistema vigente de saúde, concorrentemente com outras esferas do Poder Público;

- Monitoramento dos serviços relativos à alimentação, nutrição, saneamento básico e de saúde.

A atividade fim da SMS se realiza nas unidades de saúde, com toda a programação e execução dos planos operacionais, quais sejam, as atividades de saúde, o fornecimento de 
medicamentos, material de uso hospitalar e odontológico, médicos, dentistas, planejamento familiar, atenção à criança, atenção ao idoso, atenção à mulher, atenção ao adulto, programa de hipertensão e diabete, avaliações parciais e avaliações finais, entre outros. Sendo que as diversas coordenadorias, funcionam planejando e executando atividades-meio para suprir todas as necessidades das unidades de saúde.

\subsection{Proposta de sistema de apropriação dos custos}

O modelo conceitual do sistema de custos da SMS tem como objetivo capturar os dados originados dos diversos sistemas (SGF, pessoal, materiais, serviços de terceiros, SIS, SIA/SUS), organizar e combinar esses dados de forma a apropriá-los como custos diretos e indiretos dos objetos de custeio, no caso os postos de saúde e os procedimentos médicos.

Diante do desafio, que o Sistema de Gestão Fiscal (SGF) ainda não possuir uma contabilidade por centros de responsabilidade, os dados primários são canalizados para os objetos de custeio, através de regras e atributos de identificação, a serem definidos nos próprios sistemas existentes, nos processos das despesas liquidadas, ou criados e adaptados da própria realidade operacional da SMS. Um exemplo dessas regras e atributos está nas despesas com salários e encargos, oriundos do sistema de folha de pagamento, onde todos os servidores da SMS estão identificados por local de trabalho.

Nas despesas com materiais, o material de consumo é um dos itens mais relevantes, podendo ser perfeitamente identificado na Unidade, uma vez que a tabela do sistema único de saúde SUS, fornece os valores unitários. Os demais materiais como materiais de uso hospitalar, materiais de escritório, materiais de limpeza também poderão ser identificados de forma objetiva, porém os materiais consumidos nas atividades meio ou nos distritos sanitários deverão ser objeto de análise para definição de regras de distribuição.

\subsection{Centros de Responsabilidade e Centros de Custo na SMS}

Uma grande limitação para o desenvolvimento de qualquer sistema de custos, refere-se a quando a procedência das informações monetárias, relativas a pessoal, materiais, contratos e convênios. De modo geral, estão espalhadas em diversos subsistemas, fazendo com que o trabalho de identificação e prospecção de informações seja complexo e trabalhoso.

Para tentar confrontar essa limitação, foi preciso capturar as principais informações desde a sua origem, tratar essas informações e proceder a sua acumulação até os objetos finais de custeio. Como o sistema de custos tem um caráter gerencial, ou seja, sua principal utilidade é interna, essas pequenas imperfeições não comprometem o todo.

A proposta de simplificação é a de aglutinar setores e segregar em três níveis, conforme segue:

\section{CCA - CENTRO DE CUSTO ADMINISTRATIVO}

Os centros de custos administrativos referem-se às coordenadorias executivas existentes na própria secretaria. Estes centros compreendem os departamentos da administração central, apoio e infra-estrutura administrativa, tais como: gabinete do secretário, recursos humanos, assessorias, fundo municipal de saúde, auditoria, órgãos colegiados, apoio e promoção a saúde, regulação e avaliação. Todas essas áreas juntas dão suporte e apoio operacional aos centros de custos intermediários (Distritos Sanitários) e aos centros de custos finais (Unidades de Saúde) da SMS. 
Os centros de custos intermediários são os próprios distritos sanitários, por atuarem como intermediários entre os centros de custos administrativos e os centros de custos finais, ou seja, caso os centros de custos finais, formados pelas unidades de saúde solicitem medicamentos, a requisição destes, deverá passar primeiro pelo distrito, para que então chegue a Secretária de Saúde. Hoje a SMS, conta com 12 distritos sanitários, cada um gerenciando e dando suporte às unidades de saúde sob sua jurisdição e funcionando como uma região administrativa. Dessa forma, cada distrito fica localizado em regiões estratégicas.

\section{CCI - CENTROS DE CUSTOS FINAIS}

Os centros de custos finais da SMS são os postos de saúde. Doze distritos sanitários apoiam as unidades de saúde localizados na sua região, que compreenderam, na época do levantamento, um total de 108 unidades. Essas unidades é que executam as atividades fins da SMS, representando o próprio objeto final de custos. Com a sistemática de custos implantada na SMS, poderá se saber quantos procedimentos foram executados em determinada unidade durante um dado período, por tipo (ou categoria) de procedimento e quanto custou o pessoal, materiais e os terceiros usados.

\subsection{Descrição do modelo conceitual básico do SGC na SMS}

O modelo conceitual do SGC da SMS foi desenvolvido para contemplar as atividades de Saúde para tender todas as unidades de saúde existentes ou que venham a ser criadas ou municipalizadas. Foram usadas três unidades, adotadas como amostra. No levantamento de campo foram identificados os principais processos e atividades operacionais e administrativas de todos os centros de custos constantes do organograma oficial na Figura 1.

Para o desenvolvimento da concepção do modelo conceitual, foram identificados os principais pressupostos, ou premissas básicas, a saber:

OQUE MEDIR - Definir com o principal gestor (usuário) os objetos de custeio a serem mensurados e acompanhados. Após levantamento, assim definiram-se os principais objetos de custeio:

a) Custo da unidade de saúde por ano/mês (existem unidades com características distintas, podendo ser agrupadas através de 5 tipologias, estas de acordo com o grau de complexidade, que vão de pequenas atividades cirúrgicas a cirurgias de grande porte);

b) Custos totais e unitários por procedimentos realizados no âmbito das unidades de saúde ano/mês. 


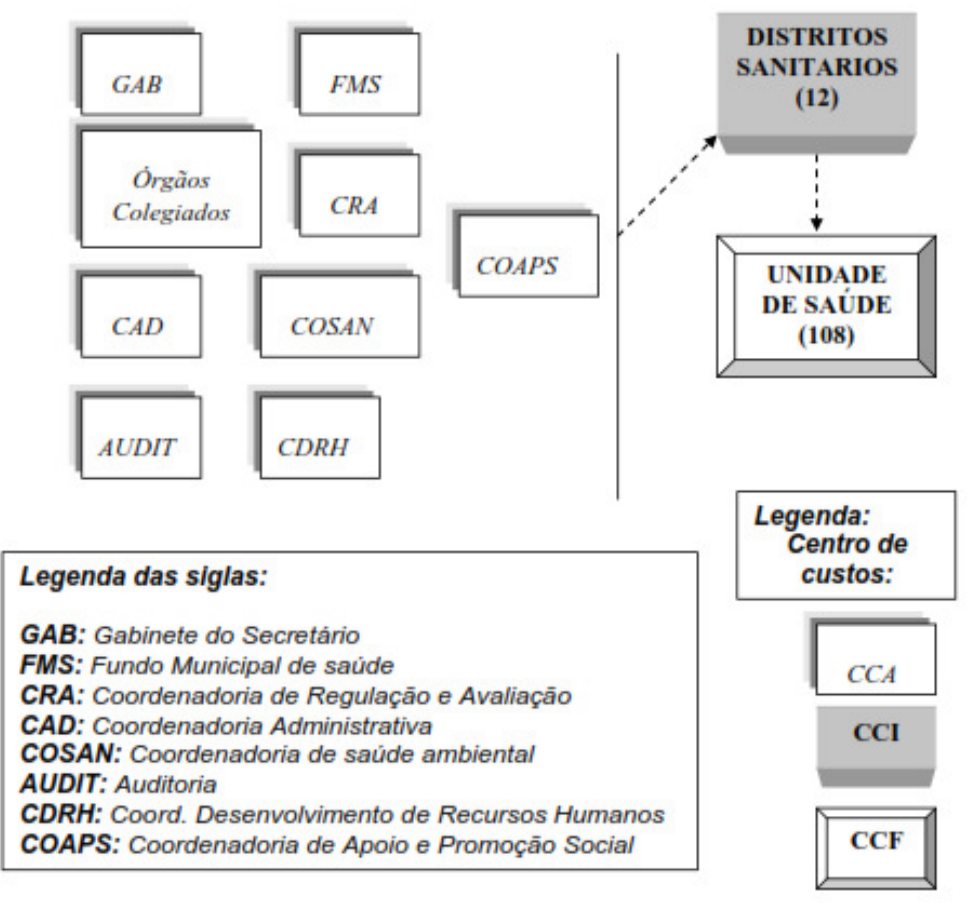

Figura 1: Estrutura Simplificada do Organograma da SMS Fonte:

ORIGEM DAS INFORMACOÕES - Identificar os sistemas e subsistemas de onde vão se originar as informações e definir a forma de obtenção destes dados, visando coletá-los e carregá-los direta ou indiretamente aos objetos finais de custeio. Sobre esse pressuposto, é apresentado, na Figura 2, a seguir, um esquema simplificado de relacionamento do sistema de custos com todos os sistemas e subsistemas da SMS.

Os dados serão obtidos de sistemas e subsistemas existentes na SMS, preferencialmente de forma integrada, pesquisando as trilhas dos códigos e campos definidos nos bancos de dados desses sistemas e criando arquivos de exportação desses dados para o sistema de custos. 


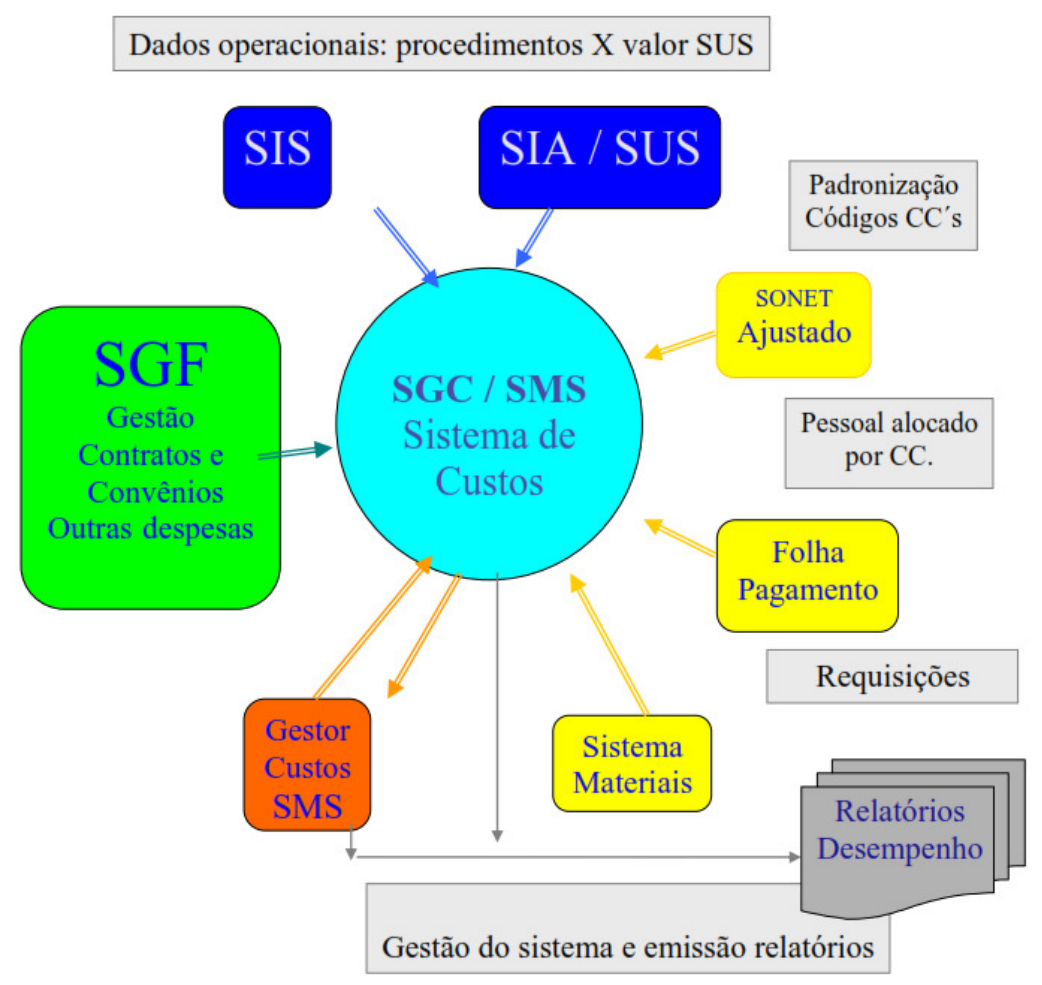

Figura 2: Esquema simplificado de inter-relacionamento do sistema de custos com os sistemas geradores de informações primárias.

Fonte:

COMO MEDIR - Identificar e detalhar os caminhos, métodos e técnicas necessárias à forma de apreensão (coleta), combinação e apropriação dos custos diretos e indiretos aos objetos de custeio. Nesse tópico concentra-se a "inteligência" do sistema de custos, ou seja, o modus operandi do sistema. Nesta etapa de forma sequencial os dados serão:

c) Coletados nos diversos sistemas de origem, mesmo que sejam alimentados de forma manual;

d) Consistidos com os totais registrados nos sistemas de origem, promovendo a consistência simultânea ou final com os dados da execução orçamentária no SGF;

e) Combinados, adaptados, compatibilizados e direcionados, de acordo com a sua directibilidade, para os diversos objetos de custeio parciais e finais;

f) Apropriados como custos diretos e indiretos aos objetos de custeio finais da SMS, quais sejam: custo por unidade de saúde/ mês e ano, custo por procedimentos/ mês e ano.

Na Figura 3, a seguir, é apresentado um esboço do sistema de custos numa concepção sistêmica: 


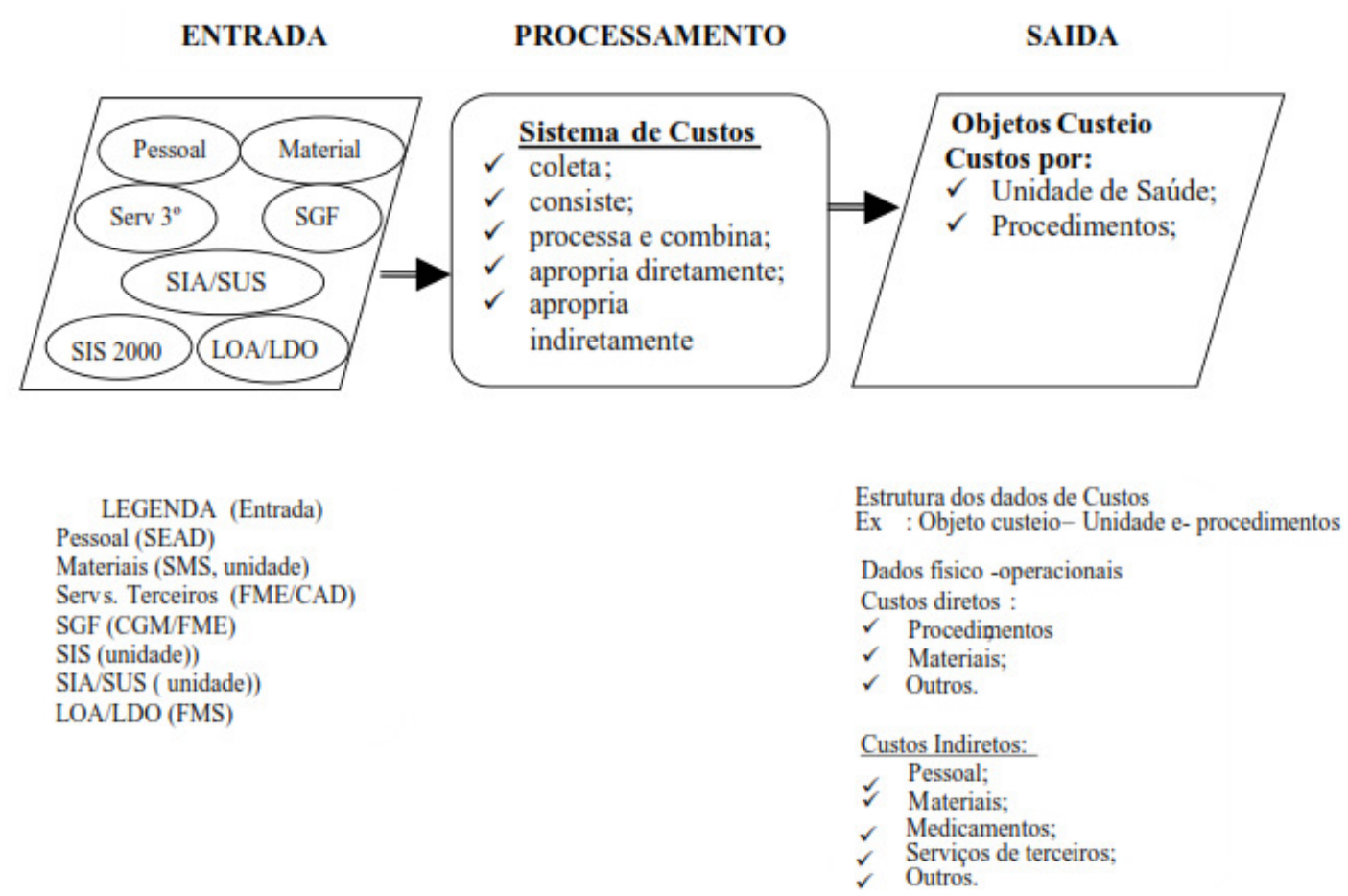

Figura 3 : Sistema de Custos: visão sistêmica simplificada Fonte:

Em síntese, o que se deseja como resultado final no sistema de custos, é obter uma informação estruturada e consistente, de quais custos podem (e como podem) ser identificados objetivamente no objeto de custeio, e quais são os demais custos que lhe serão (e como serão) atribuídos indiretamente.

\section{ANÁLISE DE RESULTADOS}

A metodologia discutida foi aplicada num município brasileiro com mais de um milhão de habitantes nos seguintes passos:

\section{$\underline{1^{o} \text { Passo }}$}

1. Levantar quantidades de procedimentos por Unidade de Saúde (SIS)

2. Identificar valor dos procedimentos da Tabela SUS

3. Apurar custos totais por procedimento e o Total Geral da Unidade (SUS)

O primeiro passo no estudo de caso para o desenvolvimento do modelo conceitual foi a escolha de uma unidade de saúde tomando como base um mês de referência, de onde foram levantados todos os procedimentos e quantidades realizadas no período. Logo após foram identificados o valor unitário de cada procedimento constantes no valor da tabela SUS, e em seguida, multiplicando-se as quantidades de determinado procedimento realizados no período em referência pelo valor unitário de cada um desses, são encontrados valores totais de cada procedimento, sendo que a soma destes formarão o total geral da unidade. 
Tabela 1.1 Estudo de caso $1^{\circ}$ passo

\begin{tabular}{|c|c|c|c|}
\hline \multirow{2}{*}{\multicolumn{3}{|c|}{$\begin{array}{l}\text { US: APM } \\
\text { Relatório dos Procedimentos mensais. }\end{array}$}} & \multirow[b]{3}{*}{ Total } \\
\hline & & & \\
\hline Procedimentos & Quant & VIr SUS & \\
\hline Vacinas & 200 & 1,0 & 200 \\
\hline Consultas tipo a & 500 & 2,5 & 1.250 \\
\hline Consultas tipo b & 300 & 3,5 & 1.050 \\
\hline Nebulização & 60 & 1,0 & 60 \\
\hline Curativo & 400 & 1,5 & 600 \\
\hline Exame laboratorio & 600 & 3,0 & 1.800 \\
\hline Extraçã̃o & 35 & 2,0 & 70 \\
\hline Tratamento de canal & 70 & 4,0 & 280 \\
\hline Raio $X$ & 90 & 1,5 & 135 \\
\hline Injeçẫo & 300 & 1,0 & 300 \\
\hline Totais & 2.555 & & 5.745 \\
\hline
\end{tabular}

Fonte:

\section{$\underline{2^{\circ} \text { Passo }}$}

Caracteriza a determinação dos custos diretos, estes dizem respeito às despesas que não necessitam de critério de rateio, para serem apropriadas a cada centro de custo. Essas despesas são visivelmente identificadas em cada centro de custos e estão classificadas conforme a Figura 4.

A despesa total com pessoal compreende todos os vencimentos, remunerações, contratações por tempo determinado, obrigações patronais, provisões e encargos sociais e outras despesas com pessoal da SMS. O elemento de despesa material de consumo engloba itens obtidos através das requisições do almoxarifado, estes itens tornam-se sub elementos de despesa, tais como: materiais de uso hospitalar, materiais de escritório, materiais de limpeza e outros.

A parte que se refere a medicamentos, está contida todos os tipos de medicamentos a serem utilizados pelos pacientes da unidade de saúde.

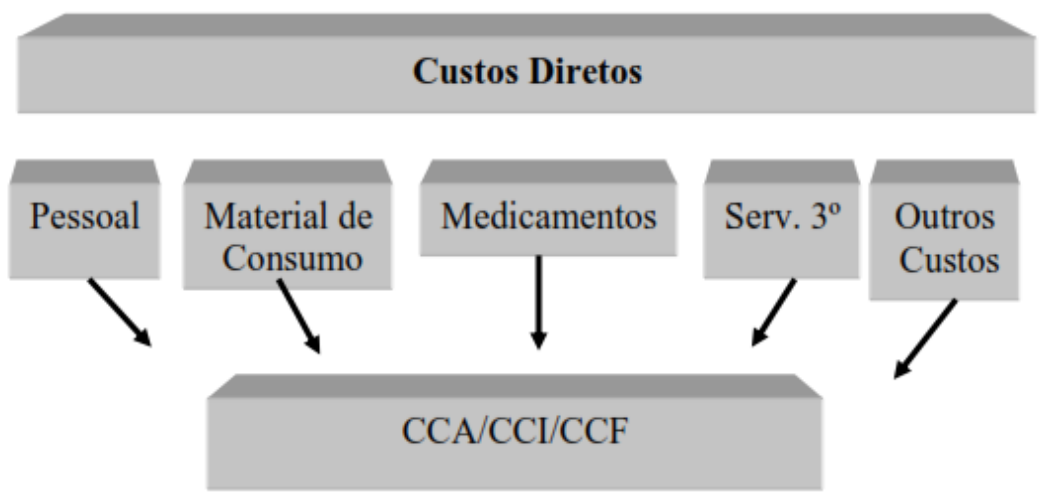

Figura 4 Determinação dos Custos Diretos da SMS

Fonte:

O módulo Serviço de Terceiros agrupa três grandes grupos: pessoa física, pessoa jurídica e serviços de consultoria. O elemento de despesa pessoa física compreende gastos com serviços médicos, apoio e combate às Doenças sexualmente transmissíveis, serviços dos agentes de saúde, estagiários entre outros. No elemento de despesa pessoa jurídica pode-se encontrar sub grupos como: vigilância e segurança, convênios e diversos contratos com empresas.

Outros Custos correspondem a gastos gerais não compreendidos nos elementos anteriores, gastos estes como: energia elétrica, água, telefone etc. 
Tabela 1.2 Estudo de caso $2^{\circ}$ passo

\begin{tabular}{|c|c|c|c|}
\hline \multirow{2}{*}{\multicolumn{3}{|c|}{\begin{tabular}{|l|l|} 
SMS & Mês: Outubro \\
Relatório de Custos por Centro de Custos \\
\end{tabular}}} & \multirow[b]{3}{*}{$\begin{array}{c}\text { CCF (US } \\
\text { APM) }\end{array}$} \\
\hline & & & \\
\hline CUSTOS & $\mathrm{CCA}$ & $\mathrm{CCl}$ & \\
\hline Pessoal & 300.000 & 61.000 & 8.000 \\
\hline Materiais & 28.500 & 8.100 & 800 \\
\hline Medicamentos & - & - & 2.000 \\
\hline Seviços terceiros & 580.000 & 120.000 & 16.000 \\
\hline Outros custos & 27.000 & 5.200 & 900 \\
\hline Totais & 935.500 & 194.300 & 27.700 \\
\hline
\end{tabular}

Fonte:

\section{$\underline{3^{o} \text { Passo e } 4^{o} \text { passo }}$}

Apresenta o critério de apropriação dos custos indiretos conforme Figura 5. Tanto o centro de custo administrativo como os centros de custo intermediários prestam serviços a área fim, portanto em razão do elo de ligação entre as unidades fins e os demais centros de custos foi utilizado como critério de alocação o somatório das quantidades de procedimentos multiplicado pelo seu valor unitário, estes formam o total geral da unidade em procedimentos.

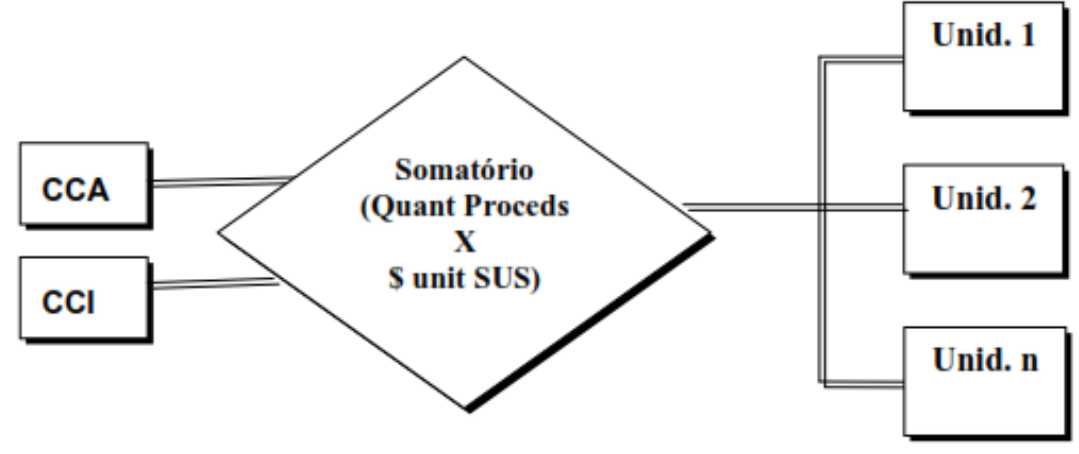

Figura 5 Base de Rateio para alocação dos Custos Indiretos dos CCA e CCI Fonte:

Assim, tomando-se por base a Unidade de saúde APM e o mês de outubro como referência, a apropriação dos custos com pessoal, materiais, medicamentos, serviços de terceiros e outros custos dos centros de custos administrativos, foram distribuídas utilizando como base o valor de 5.745 e 559.838 estabelecidos na tabela 1.3 e que corresponde respectivamente ao valor total dos procedimentos realizados no período na unidade APM e o valor total dos procedimentos de todas as unidades. 
Tabela 1.3 Estudo de caso $3^{\circ}$ passo

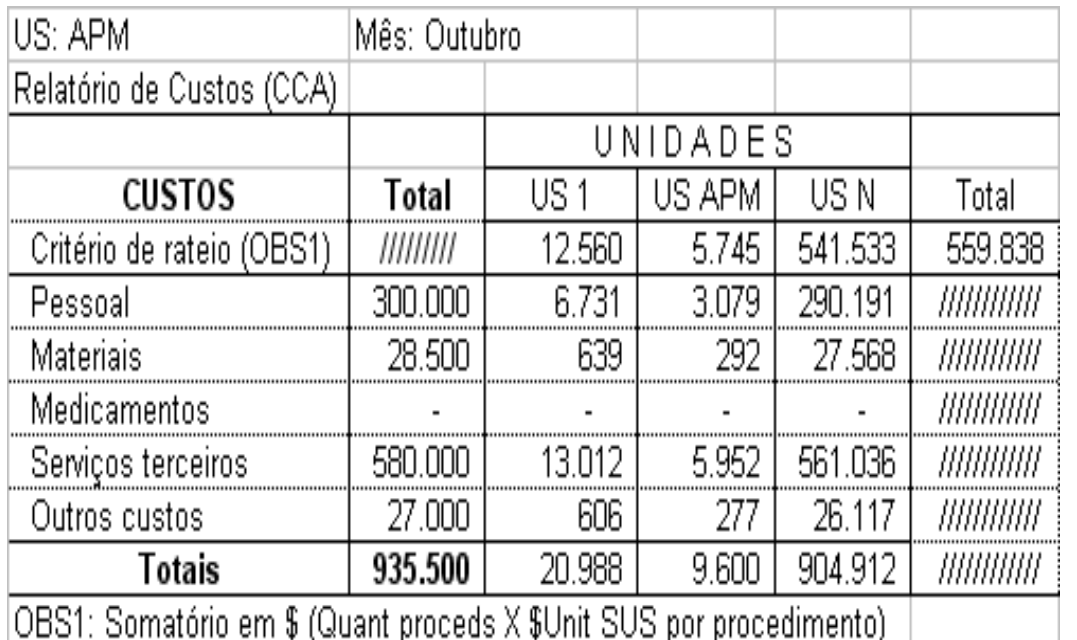

Fonte:

Do mesmo modo que foram apropriados os custos dos centros de custos administrativos ao objeto final de custeio, ocorre a apropriação dos centros de custos intermediários. Como as unidades de saúde 1, APM e $\mathrm{N}$ fazem parte do distrito Barris, esse distrito é o próprio centro de custo intermediário, de onde serão apropriados os gastos com pessoal, materiais, medicamentos etc, as unidades de saúde, conforme tabela 1.4.

Tabela 1.4 Estudo de caso $4^{\circ}$ passo

\begin{tabular}{|c|c|c|c|c|c|}
\hline \multirow{3}{*}{$\begin{array}{l}\text { US: APM } \\
\text { Relatório de Custos (CCl) } \\
\end{array}$} & \multicolumn{2}{|c|}{ Mês: Outubro } & & & \\
\hline & \multicolumn{2}{|c|}{ Distrito Barris } & & & \\
\hline & & \multicolumn{3}{|c|}{ UNIDADES } & \\
\hline CUSTOS & Total & US 1 & US APM & USN & Total \\
\hline Critério de rateio (OBS1) & $\| I I I I I I I$ & 12.560 & 5.745 & 51.461 & 69.766 \\
\hline Pessoal & 61.000 & 10.982 & 5.023 & 44.995 & II//////I \\
\hline Materiais & 8.100 & 1.458 & 667 & 5.975 & II//////I \\
\hline Medicamentos & - & - & - & - & II//////I \\
\hline Sevicos terceiros & 120.000 & 21.604 & 9.882 & 88.515 & II/////I/ \\
\hline Outros custos & 5.200 & 936 & 428 & 3.836 & II//////I \\
\hline Totais & 194.300 & 34.980 & 16.000 & 143.320 & ' $/ / / / / / / / / / 1$ \\
\hline
\end{tabular}

Fonte:

\section{$\underline{5^{\circ} \text { Passo }}$}

Corresponde a totalização da unidade de saúde após o levantamento de todos os custos diretos da unidade de saúde, incorporados com os demais custos indiretos dos centros de custos administrativos e intermediários, que lhe foram apropriados. 


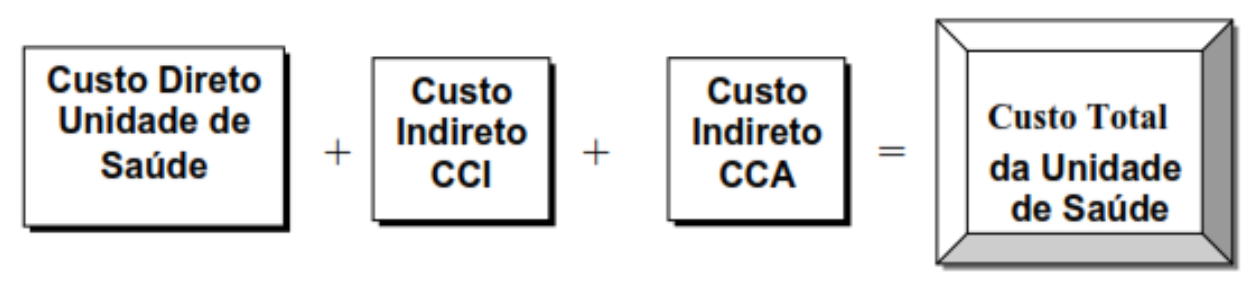

Figura 6 Totalização por Unidade de Saúde

Fonte:

Conforme explicitado no $5^{\circ}$ passo e identificado na Figura 6 a aplicação ficaria plenamente desenvolvida na SMS, como mostra a tabela 1.5.

Tabela 1.5 Estudo de caso $5^{\circ}$ passo

\begin{tabular}{|c|c|c|c|c|}
\hline \multirow{2}{*}{\multicolumn{3}{|c|}{\begin{tabular}{l|l} 
US: APM & Mês: Outubro \\
Relatório de Custos Totais da US APM \\
\end{tabular}}} & \multirow[b]{3}{*}{$\begin{array}{c}\text { CCA } \\
\text { (Rateio) }\end{array}$} & \multirow[b]{3}{*}{ Total } \\
\hline & & & & \\
\hline CUSTOS & CCF & $\begin{array}{c}\mathrm{CCl} \\
\text { (Rateio) }\end{array}$ & & \\
\hline Pessoal & 8.000 & 5.023 & 3.079 & 16.102 \\
\hline Materiais & 800 & 667 & 292 & 1.759 \\
\hline Medicamentos & 2.000 & - & - & 2.000 \\
\hline Seviços terceiros & 16.000 & 9.882 & 5.952 & 31.834 \\
\hline Outros custos & 900 & 428 & 277 & 1.605 \\
\hline Totais & 27.700 & 16.000 & 9.600 & 53.300 \\
\hline CCF: Centros de C & & & & \\
\hline $\mathrm{CCl}$ : Centros de $\mathrm{Cu}$ & mediários & & & \\
\hline CCA: Centros de $\mathrm{Cl}$ & inistrat & & & \\
\hline
\end{tabular}

Fonte:

\section{$\underline{6^{0} \text { Passo }}$}

Por fim, o ultimo passo, concluiu-se com a distribuição dos custos totais e apresentação dos custos reais do período por procedimentos e consequentemente do custo total real da unidade de saúde. O calculo da distribuição é feita utilizando como critério o valor total da unidade de saúde em razão do valor total unitário de cada espécie de procedimento multiplicando-se pelas quantidades realizadas no período, encontrando-se o valor da unidade de saúde por procedimentos, conforme demonstrado na Figura 7.

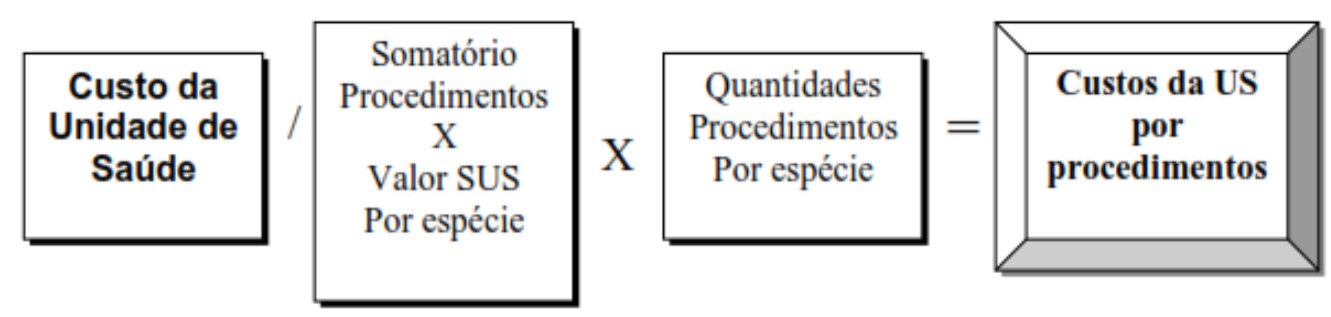

Figura 7 Cálculo da distribuição e totalização da unidade por procedimentos Fonte:

Demonstra-se na tabela 1.6, em síntese, como foi feita a distribuição dos custos levando em consideração o memorial de calculo. 
Tabela 1.6 Estudo de caso $6^{\circ}$ passo

\begin{tabular}{|c|c|c|c|c|c|}
\hline \multirow{2}{*}{\multicolumn{6}{|c|}{$\begin{array}{l}\text { US: APM Mês: Outubro } \\
\text { Relatório de anuracẫo do custo total }\end{array}$}} \\
\hline & & & & & \\
\hline Procedimentos & Quant & Vir SUS & Total & Ctot & Vir tot/proc \\
\hline Vacinas & 200 & 1,0 & 200 & 1.856 & 9,3 \\
\hline Consultas tipo a & 500 & 2,5 & 1.250 & 11.597 & 23,2 \\
\hline Consultas tipo $b$ & 300 & 3,5 & 1.050 & 9.742 & 32,5 \\
\hline Nebulizaçẩo & 60 & 1,0 & 60 & 557 & 9,3 \\
\hline Curativo & 400 & 1,5 & 600 & 5.567 & 13,9 \\
\hline Exame laboratorio & 600 & 3,0 & 1.800 & 16.700 & 27,8 \\
\hline Extraçẵo & 35 & 2,0 & 70 & 649 & 18,6 \\
\hline Tratamento de canal & 70 & 4,0 & 280 & 2.598 & 37,1 \\
\hline Raio $X$ & 90 & 1,5 & 135 & 1.252 & 13,9 \\
\hline Injeçẩo & 300 & 1,0 & 300 & 2.783 & 9,3 \\
\hline Totais & 2.555 & $\mid / / / / / / /$ & 5.745 & 53.300 & {$[/ / / / / / /$} \\
\hline
\end{tabular}

Fonte:

O gestor do órgão poderá identificar o que ocasionou o aumento dos procedimentos e assim procurar da melhor maneira possível gerenciar todos os recursos, entre as diversas analises que poderão ser feitas.

\section{CONCLUSÕES E CONSIDERAÇÕES FINAIS}

O trabalho apresenta um caso real de implantação de um sistema de acumulação de custos desenvolvido "in locu" numa Secretaria Municipal de Saúde (SMS). A despeito de limitações de ordem técnica e política, foram identificadas motivações para que os entes públicos busquem implantar um sistema de custos. Entre estas estão: a) o dever de prestar contas (accountability) de maneira transparente e objetiva à sociedade, e b) a pressão pela profissionalização da gestão pública. Adicionalmente, discutiu-se de forma abrangente os principais benefícios de um sistema de custos no setor público, destacando-se: i) a melhoria do processo de planejamento; ii) o aproveitamento ou redução da capacidade ociosa e iii) o controle da economicidade das operações.

A análise comparativa entre as metodologias de custos indicou que no curto prazo o mais apropriado é o custeio por absorção com departamentalização e, no médio a longo prazo, o custeio baseado em atividades, representa um ideal a ser atingido.

Com a caracterização organizacional e operacional da SMS é apresentado um modelo conceitual, estruturado desde o seu diagnóstico inicial, incorporando um plano de intervenção e os resultados apurados com base em levantamento de dados "in locu". Uma vez identificados os objetivos norteadores, foi realizada uma investigação minuciosa nos dados da contabilidade e nos dados operacionais de cerca de unidades de saúde.

$\mathrm{Na}$ apresentação das tabelas com os valores do levantamento de campo, mostra-se toda a seqüência de operações que culminam com a determinação dos custos acumulados de toda a estrutura da SMS por unidade e por procedimento.

Esta pesquisa, à guisa de conclusão, serve como provocação para que mais experiências sejam trazidas à baila para análise, discussão e aperfeiçoamento dos propósitos e dos meios profissionais e acadêmicos para se desenvolver soluções para a implantação de sistemas de custos no setor público. A sociedade está ansiosa por novos tempos em que a chamada "nova gestão pública" se constitua num objetivo permanente da administração pública, onde os fantasmas da corrupção, dos desvios de erário público e dos desperdícios sejam minimizados e concentrados nos fins a que eles se propõem. 


\section{REFERÊNCIAS}

ALONSO, MARCOS, Custo no Serviço Público. Texto para Discussão, n. 31. Brasilia, Enap, 1998.

HOLANDA, Victor, LATTMANN-WELTMAN, Fernando; GUIMARÃES, Fabricia (org.) Sistema de Informação de Custos na administração Pública Federal: uma política de Estado FGV, 2010

MACHADO, N, Sistema de Informação de Custos: Diretrizes para Integração ao Orçamento Público e à Contabilidade Governamental. Brasília. Enap, 2005.

MACHADO, N., HOLANDA, V., Diretrizes e modelo conceitual de custos para o setor público a partir da experiência no governo federal do Brasil, Revista de Administração Publica, 44(4), p. 791-820, 2010

MARTINS, Eliseu. Contabilidade de Custos. 9. ed. - São Paulo: Atlas, 2003.

PIGATTO, José A M ; HOLANDA, V. B. ; MOREIRA, C. R. ; CARVAlHO, F. A. . A Importância da contabilidade por competência para a informação de custos governamental. Revista de Administração Pública, v. 44, p. 821-837, 2010.

ROEHL-ANDERSON J; BRAGG S, Controllership, The Work of the Managerial Accountant, John Willey \& Sons, $9^{\text {th }}$. Edition, 2009.

SILVA, Lino Martins da. Contribuição ao estudo para implantação de sistema de custeamento na administração pública. 203f - Universidade Gama Filho, 1997.

SLOMSKI, Valmor. Manual de contabilidade pública: um enfoque na contabilidade municipal, de acordo com a lei de responsabilidade fiscal. 2. ed. - SP: Atlas, 2009. 